\title{
Transcriptional regulation of lipid synthesis in bovine mammary epithelial cells by sterol regulatory element binding protein-1
}

\author{
L. Ma and B. A. Corl ${ }^{1}$ \\ Department of Dairy Science, Virginia Tech, Blacksburg 24061
}

\begin{abstract}
The objective of this study was to investigate the transcriptional regulation of lipid synthesis by sterol regulatory element binding protein-1 (SREBP-1) in bovine mammary epithelial cells. In the current study, bovine mammary epithelial (MAC-T) cells cultured in insulin- and prolactin-containing medium were treated with a transfection reagent as control, a nontargeting small interfering (si)RNA sequence $(100 \mathrm{n} M)$ as a negative control, or an SREBP-1-specific siRNA (100 $\mathrm{n} M$ ) for $48 \mathrm{~h}$. The mRNA expression of SREBP-1 was decreased more than $90 \%$ by siRNA. Precursor and mature forms of SREBP-1 protein were undetectable in cells treated with SREBP-1 siRNA. Fatty acid synthesis and fatty acid uptake, measured using isotope incorporation, were reduced significantly in cells treated with SREBP-1 siRNA compared with controls. Transcript abundance of acyl-CoA synthetase shortchain family member 2 , acetyl-CoA carboxylase, fatty acid synthetase, and isocitrate dehydrogenase 1 (key enzymes of de novo lipogenesis) was decreased by 40 to $65 \%$ with SREBP-1 siRNA, in agreement with acetate incorporation data. The mRNA levels of fatty acid binding protein 3 and stearyl-CoA desaturase 1 (proteins responsible for intracellular fatty acid trafficking and long-chain fatty acid modification) were decreased 76 and $60 \%$, respectively, by SREBP-1 siRNA treatment compared with controls. The mRNA expression of mitochondrial glycerol-3-phosphate acyltransferase and lipin 1 (involved in triglyceride synthesis) was significantly decreased in cells treated with SREBP-1 siRNA compared with control cells. However, the expression of milk fat globule membrane proteins measured did not differ among treatments. In conclusion, SREBP-1 plays an important role in integrated regulation of lipid synthesis in bovine mammary epithelial cells through regulation of key enzymes.
\end{abstract}

Received October 24, 2011.

Accepted February 29, 2012.

${ }^{1}$ Corresponding author: bcorl@vt.edu
Key words: sterol regulatory element binding protein-1 (SREBP-1), small interfering RNA, milk fat

\section{INTRODUCTION}

Milk fat is the major energy component of milk, and regulation of its synthesis has been of interest to many research groups because milk fat is important for processing and flavor aspects of milk. Two sources of FA exist for milk fat synthesis: de novo FA synthesized by mammary epithelial cells and preformed FA from the digestive tract or body fat mobilization. In cows, about one-half of FA, including short-chain FA (4-8 carbons), medium-chain FA (10-14 carbons), and a portion of 16-carbon FA, come from de novo FA synthesis, with acetate and $\beta$-hydroxybutyrate as the precursors. The other half, including remaining 16-carbon FA and FA with more than 16 carbons, are preformed FA taken up from circulation by the mammary gland (Bauman and Griinari, 2003). Although much is known about the synthesis of milk fat, its regulatory pathways are still not well understood (Rudolph et al., 2007).

Milk fat synthesis is highly regulated by dietary factors, and milk fat depression (MFD) is one example of dietary regulation of milk lipid synthesis. Milk fat depression is a syndrome in which milk fat content is reduced up to $50 \%$ when cows are fed readily fermentable diets, such as high-concentrate/low-fiber diets, or diets supplemented with fish oil or plant oil. However, other components in milk and milk yield are not affected (Peterson et al., 2003). Bauman and Griinari (2003) proposed that intermediates from alternative ruminal biohydrogenation pathways of PUFA exhibit inhibitory effects on milk fat synthesis. Among the intermediates, trans-10,cis-12 conjugated linoleic acid (CLA) is a potent mediator of the inhibition of milk fat synthesis during MFD (Baumgard et al., 2000; Peterson et al., 2002). Reduction in mRNA abundance of genes encoding enzymes involved in FA transport and uptake, de novo FA synthesis, desaturation of FA, and triglyceride synthesis has been associated with MFD (Baumgard et al., 2002).

Several transcription factors can regulate FA synthesis. One family of transcription factors designated 
sterol regulatory element binding proteins (SREBP), which belong to the basic helix-loop-helix leucine zipper family, are known to regulate FA synthesis (Shimano, 2001). Three isoforms of SREBP have been identified: SREBP-1a, SREBP-1c, and SREBP-2. Both SREBP$1 \mathrm{a}$ and SREBP-1c are transcribed from the same gene with alternative splicing; SREBP-1c and SREBP-1a use different first exons and both regulate FA synthesis. Sterol regulatory element binding protein-2 is transcribed from a separate gene and regulates the cholesterol biosynthetic pathway. All SREBP are translated as precursor proteins residing in the endoplasmic reticulum membrane and are activated by proteolytic cleavage in the Golgi to release the mature SREBP protein that can translocate to the nucleus and bind to the promoter of target genes to induce their transcription (Eberlé et al., 2004).

The transcription of many genes involved in milk fat synthesis is downregulated during MFD, and SREBP-1 has been implicated in mediating these effects. This is supported by studies showing that the nuclear SREBP-1 protein was reduced when a bovine mammary epithelial cell line was treated with trans10,cis-12 CLA (Peterson et al., 2004). Transcriptional regulation of $\mathrm{FA}$ synthesis may be mediated by several different factors. The exact, independent role of each factor has not been previously established. Thus, our objective was to reveal the specific role of SREBP-1 in regulating lipid synthesis in bovine mammary epithelial cells independent of CLA-induced reductions in lipid synthesis. In this study, knockdown of SREBP-1 in a bovine mammary epithelial cell line (MAC-T) was achieved using a double-stranded small interfering RNA (siRNA), with 21 to 23 nucleotides, designed specifically to reduce SREBP-1 expression.

\section{MATERIALS AND METHODS}

\section{Cell Culture and Treatments}

Experiments were performed using the MAC-T bovine mammary epithelial cell line. Basal culture medium consisted of high-glucose Dulbecco's modified Eagle's medium supplemented with $10 \%$ fetal bovine serum, $10 \mathrm{kU} / \mathrm{mL}$ of penicillin, $10 \mathrm{mg} / \mathrm{mL}$ of streptomycin, and $25 \mu \mathrm{g} / \mathrm{mL}$ of amphotericin. For hormonal medium, fetal bovine serum was removed from basal medium and hormones $(0.1 \mu \mathrm{g} / \mathrm{mL}$ of insulin and $1.5 \mu \mathrm{g} / \mathrm{mL}$ of prolactin; Sigma Chemical Co., St. Louis, MO) were added. Cells were routinely cultured at $37^{\circ} \mathrm{C}$ with $5 \%$ $\mathrm{CO}_{2}$ and basal medium was applied.

For experiments, cells were seeded in 6 -well plates at a density of $2 \times 10^{4}$ cells $/ \mathrm{cm}^{2}$. After overnight incubation in basal medium, cells were switched to hormonal medium and siRNA (Dharmacon, Thermo Fisher Scientific Inc., Waltham, MA) were delivered to cells by Transfection Reagent \#2 (Dharmacon) at $100 \mathrm{nM}$ according to the manufacturer's protocol. Treatments included specific anti-SREBP-1 siRNA (SSI; ccacaacgccaucgagaaauu and gcaccgaggccaaguugaauu), siRNA with a random sequence as negative control (NEG), and transfection reagent alone as untransfected control (UNT). Treated cells were incubated for $48 \mathrm{~h}$ and then harvested for analysis. Experiments were repeated 3 to 4 times.

\section{RNA Extraction and Real-Time Quantitative PCR}

Total RNA was extracted from cells using TRI Reagent (Molecular Research Center Inc., Cincinnati, OH) according to the manufacturer's instructions. After extraction, ribonucleic acid pellets were resuspended in RNase-free water and concentrations were determined using a NanoDrop 1000 spectrophotometer (Thermo Fisher Scientific Inc., Wilmington, DE). Then, RNA (1 $\mathrm{\mu g}$ per reaction) was reverse transcribed to complementary DNA using the Omniscript RT kit (Qiagen, Valencia, CA) according to the manufacturer's instructions. Oligo-dT (Eurofins MWG/Operon, Huntsville, $\mathrm{AL}$ ) was used as the primer for reverse transcription. Real-time quantitative PCR was performed using the Quantitect SYBR Green PCR kit (Qiagen) in an Applied Biosystems 7300 real-time PCR machine (Applied Biosystems, Foster City, CA). Reactions were as follows: 1 cycle at $95^{\circ} \mathrm{C}$ for $10 \mathrm{~min}$, followed by 40 cycles at $95^{\circ} \mathrm{C}$ for $30 \mathrm{~s}, 58^{\circ} \mathrm{C}$ for $30 \mathrm{~s}$, and $72^{\circ} \mathrm{C}$ for 1 min. Each reaction was performed in duplicate wells. $\beta$-Actin was used as the endogenous control gene, and fold change was calculated using $2^{-\Delta \Delta \mathrm{Ct}}$ method (Livak and Schmittgen, 2001) with UNT as the calibrator. Gene-specific primers for the transcripts used in the study are shown in Table 1.

\section{Protein Extraction and Immunoblotting}

Cells were harvested in cold lysis buffer (50 $\mathrm{m} M$ Tris, $\mathrm{pH} 7.4,0.5 \%$ Triton X-100, $0.3 \mathrm{M} \mathrm{NaCl}, 2 \mathrm{~m} M$ EDTA, $\mathrm{pH}$ 8.0, and protease inhibitor), followed by centrifugation at $16,100 \times g$ for $15 \mathrm{~min}$ at $4^{\circ} \mathrm{C}$. Supernatants were collected for protein concentration measurements. Protein concentrations were determined using the Bradford assay (Bio-Rad, Hercules, CA). To ensure equal loading, samples were diluted to the same protein concentrations with Laemmli sample buffer (Sigma Chemical Co.) and heated at $95^{\circ} \mathrm{C}$ for $10 \mathrm{~min}$. Proteins were separated by electrophoresis using polyacrylamide gels $[7.5 \%$ gel for acetyl-CoA carboxylase (ACC) and $12 \%$ gel for SREBP-1 and stearoyl-CoA desaturase 
Table 1. Primer sequences for transcripts used in real-time quantitative PCR

\begin{tabular}{|c|c|c|c|}
\hline Transcript & Accession number & Primers $\left(5^{\prime}\right.$ to $\left.3^{\prime}\right)$ & \\
\hline \multirow[t]{2}{*}{ Actin } & AY141970 & Forward & ctcttccagccttccttcct \\
\hline & NM_001113302 & $\begin{array}{l}\text { Reverse } \\
\text { Forward }\end{array}$ & $\begin{array}{l}\text { gggcagtgatctctttctgc } \\
\text { atgccatcgagaaacgctac }\end{array}$ \\
\hline SREBP-1 & NM__OUIIDJ0 & Reverse & gtccgcagactcaggttctc \\
\hline \multirow[t]{2}{*}{ FABP3 } & NM_174313.2 & Forward & aagcctaccacaatcatcgaag \\
\hline & & Reverse & ttcaagctgggagtcgagttc \\
\hline \multirow[t]{2}{*}{ SCD1 } & AY241933 & Forward & ccctttccttgagctgtctg \\
\hline & & Reverse & atgctgactctctccectga \\
\hline \multirow[t]{2}{*}{$\mathrm{ACC}$} & NM_174224 & Forward & gggtgaaagactgggttgaa \\
\hline & & Reverse & gacagagcacggatgtgatg \\
\hline \multirow[t]{2}{*}{ FAS } & NM_001012669 & Forward & ctgcaactcaacgggaactt \\
\hline & & Reverse & aggctggtcatgttctccag \\
\hline \multirow[t]{2}{*}{ GPAM } & AY515690 & Forward & attgacccttggcacgatag \\
\hline & & Reverse & aacagcaccttcccacaaag \\
\hline \multirow[t]{2}{*}{ DGAT1 } & AY065621 & Forward & gacacagacaaggacggaga \\
\hline & & Reverse & cagcatcaccacacaccaa \\
\hline \multirow[t]{2}{*}{ AGPAT6 } & NM_001083669 & Forward & aagcaagttgcccatcctca \\
\hline & & Reverse & agctttaacctcggtgtcaaa \\
\hline \multirow[t]{2}{*}{ ACSS1 } & BC114698 & Forward & gatgatgtgggtgatgtgga \\
\hline & & Reverse & ccagaccgagtttttggaag \\
\hline \multirow[t]{2}{*}{ ACSS2 } & BC134532 & Forward & ggactgaaacagggaagcaa \\
\hline & & Reverse & cgcacaagagaagcaacaaa \\
\hline \multirow[t]{2}{*}{ ACSL1 } & NM_001076085 & Forward & tggcccatatgtttgagaga \\
\hline & & Reverse & gggccttgagatcatccata \\
\hline \multirow[t]{2}{*}{ IDH1 } & NM_181012 & Forward & cgatgagaagagagtggagga \\
\hline & & Reverse & caagccggggtatattttg \\
\hline \multirow[t]{2}{*}{ BTN1A1 } & NM_174508 & Forward & agcccetgtttcttcctgtt \\
\hline & & Reverse & tgccgacctaactccatctt \\
\hline \multirow[t]{2}{*}{ S14 } & NM_001040533 & Forward & gaggaggagagcgtgttgg \\
\hline & & Reverse & tcagaggaaggtagggagga \\
\hline \multirow[t]{2}{*}{ LPIN1 } & XM_002707716 & Forward & gaggggaagaaacaccacaa \\
\hline & & Reverse & gtagctgacgctggacaaca \\
\hline \multirow[t]{2}{*}{ PLIN2 } & NM_173980 & Forward & tggtctcctcggettacatc \\
\hline & & Reverse & tcttttgccccagtcatagc \\
\hline
\end{tabular}

(SCD1); Cambrex Corporation, East Rutherford, NJ] and transferred to a polyvinyl difluoride membrane using a Bio-Rad Trans-Blot SD semi-dry transfer cell (Bio-Rad). Membranes were then blocked in blocking buffer $(0.05 M$ Tris, pH $7.4,0.2 \mathrm{M} \mathrm{NaCl}, 0.1 \%$ Tween, and $5 \%$ nonfat dry milk) on a rocker for $1 \mathrm{~h}$ at room temperature. Membranes were probed with primary anti-SREBP-1 antibody (SC-13551, Santa Cruz Biotechnology, Santa Cruz, CA), primary anti-ACC antibody (Cell Signaling Technology, Beverly, MA), or primary anti-SCD1 antibody (custom rabbit antibovine SCD1, Pacific Immunology, Ramona, CA) at 1:1,000 in blocking buffer at $4^{\circ} \mathrm{C}$ overnight. Membranes were washed in washing buffer $(0.05 M$ Tris, $\mathrm{pH}$ 7.4, 0.2 $M \mathrm{NaCl}$, and $0.1 \%$ Tween) twice for $10 \mathrm{~min}$. Following washing, membranes were incubated with horseradish peroxidase-conjugated goat, anti-mouse or anti-rabbit secondary antibody (Santa Cruz Biotechnology) at 1:1,000 in blocking buffer for $1 \mathrm{~h}$ at room temperature. Membranes were washed 3 times, for 15 min each, and proteins were detected using ECL-Plus chemiluminescence substrate (Amersham Biosciences, Pittsburgh, PA) according to the manufacturer's instructions.
Chemiluminescence was measured using a Chemidoc XRS digital imaging system and densitometry was performed using Quantity One software (Bio-Rad).

\section{FA Synthesis Assay}

De novo FA synthesis was determined by quantifying the incorporation of $\left[1-{ }^{14} \mathrm{C}\right]$-acetate (MP Biomedicals, Solon, $\mathrm{OH}$ ) into lipids. Methods were adapted from Peterson et al. (2004) with modifications. After cells were transfected with siRNA for $44 \mathrm{~h}$, medium was removed and replaced with fresh medium containing $0.3 \mathrm{mM}$ acetate and $\left[1-{ }^{14} \mathrm{C}\right]$-labeled acetic acid to a final concentration of $1 \mu \mathrm{Ci}$ /well and incubated for 4 h. After incubation, isotope-containing medium was removed and cells were washed with $1 \times$ PBS. Cells then were lysed with SDS buffer (0.1\% in PBS) and lipids from the lysates were extracted with hexaneisopropanol (3:2). The organic phase was transferred to scintillation vials. Scintillation cocktail $(15 \mathrm{~mL}$ per vial; Scintisafe 30\% Cocktail, Fisher Scientific) was added to scintillation vials. Radioactivity was measured using a LS 6000LL Beckmann scintillation counter (Beckmann 
Coulter Inc., Brea, CA). Activity was calculated and expressed as nanomoles of acetate incorporated per $4 \mathrm{~h}$.

\section{FA Uptake Assay}

Fatty acid uptake was measured by quantifying the incorporation of $\left[1-{ }^{14} \mathrm{C}\right]$-oleate (MP Biomedicals) into lipids. Uptake of $\left[1-{ }^{14} \mathrm{C}\right]$-labeled oleate was measured as described for $\left[1-{ }^{14} \mathrm{C}\right]$-acetate incorporation. Oleate (Matreya LLC, Pleasant Gap, PA) was bound to BSA (Sigma Chemical Co.) using the method described by Ip and coworkers (1999) with modifications. Briefly, pure oleate was weighed and mixed with $0.05 \mathrm{M} \mathrm{NaOH}$. The resulting sodium salt was complexed with BSA solution at a $3: 1$ molar ratio to a final concentration of $100 \mu \mathrm{M}$ oleate and $1 \mu \mathrm{Ci} /$ well $\left[1-{ }^{14} \mathrm{C}\right]$-labeled oleate.

\section{Statistical Analysis}

All data were analyzed using the Mixed procedure (SAS 9.2; SAS Institute Inc., Cary, NC). The model included the fixed effect of treatment and the random effect of replicate. Treatment means were compared using orthogonal contrasts [UNT vs. NEG and (UNT + NEG) vs. SSI]. Differences were considered significant when $P<0.05$.

\section{RESULTS}

The mRNA abundance of SREBP-1 was decreased more than $90 \%$ when MAC-T cells were transfected with SREBP-1-specific siRNA (Figure 1A). Both precursor and mature forms of SREBP-1 protein were undetectable from SREBP-1 siRNA-treated cells, whereas abundant protein was present in control cells (Figure 1B), indicating the effectiveness of siRNA in reducing SREBP-1 mRNA abundance. The mRNA expression of spot 14 (S14) declined dramatically with SREBP-1 siRNA treatment, and this was also observed in the negative control (Figure 1C). Cells with SREBP-1 knockdown had significantly less FA synthesis and uptake compared with controls, as shown by acetate (Figure 1D) and oleate (Figure 1E) incorporation data.

Because acetate is the substrate for the de novo lipogenic pathway and we observed a reduction in acetate incorporation, we examined the mRNA abundance of genes encoding enzymes that play key roles in the de novo lipogenic pathway. Levels of mRNA of acyl-CoA synthetase short-chain family member 2 (ACSS2), ACC, fatty acid synthetase (FAS), and isocitrate dehydrogenase 1 (IDH1) were reduced by $60,40,65$, and $50 \%$, respectively, by SREBP-1 siRNA treatment compared with controls (Figure $2 \mathrm{~B}$ to $2 \mathrm{E}$ ).
Protein expression of ACC was also reduced by approximately $50 \%$ in cells treated with SREBP-1 siRNA (Figure 3A). However, mRNA expression of acyl-CoA synthetase short-chain family member 1 (ACSS1) was not changed when SREBP-1 was knocked down (Figure $2 \mathrm{~A})$.

To evaluate the effect of SREBP-1 on the expression of enzymes involved in long-chain FA activation, transport, and desaturation, we also analyzed the mRNA levels of acyl-CoA synthetase long-chain family member 1 (ACSL1), fatty acid binding protein 3 (FABP3), and SCD1. Among these transcripts, we observed no difference between SREBP-1 siRNA treatment and controls for ACSL1 (Figure 4A). However, mRNA levels of FABP3 and SCD1 were decreased by 76 and $60 \%$, respectively, in cells transfected with siRNA specific for SREBP-1 (Figure 4B and 4C). Additionally, SCD1 protein level was decreased more than $90 \%$ when SREBP-1 was inhibited by siRNA compared with controls (Figure 3B).

After synthesis and activation, FA are esterified to glycerol-3-phosphate to produce triglycerides. Enzymes responsible for triglyceride esterification, including mitochondrial glycerol-3-phosphate acyltransferase (GPAM), 1-acylglycerol-3-phosphate-O-acyltransferase 6 (AGPAT6), lipin 1 (LPIN1), and diacylglycerol acyltransferase 1 (DGAT1), were examined in the current study. Levels of mRNA for GPAM and LPIN1 were decreased by about 20 and 90\%, respectively, when cells were transfected with specific anti-SREBP-1 siRNA (Figure 5A and 5C). However, the expression of AGPAT6 and DGAT1 were increased in SREBP-1 siRNA-treated cells compared with the control cells (Figure 5B and 5D).

Milk fat is secreted as a globule surrounded by the milk fat globule membrane and proteins such as perilipin 2 (PLIN2) and butyrophilin subfamily 1 member A1 (BTN1A1). To investigate the role of SREBP-1 in transcription of milk fat globule protein genes, we measured the mRNA expression of PLIN2 and BTN1A1 with SREBP-1 knockdown. The abundance of mRNA for PLIN2 was upregulated in cells transfected with SREBP-1 siRNA (Figure 6A). However, the mRNA expression of BTN1A1 was not changed, but showed a trend for downregulation with SREBP-1 siRNA treatment $(P=0.06$; Figure $6 \mathrm{~B})$.

\section{DISCUSSION}

Different SREBP isoforms have different roles in regulating lipid synthesis, with SREBP-1a being responsible for regulating both FA and cholesterol synthesis, whereas SREBP-1c and SREBP-2 contribute to 
A

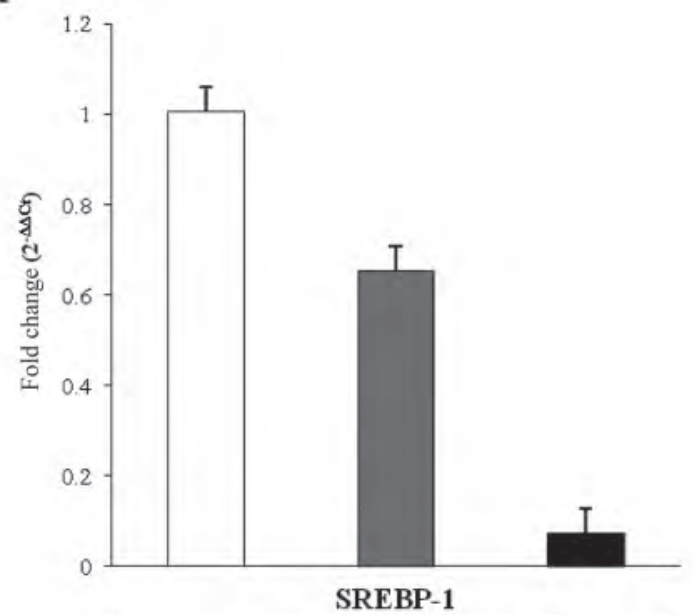

\begin{tabular}{|c|c|}
\hline Contrast & $P$ value \\
\hline (UNT+NEG) vs. SSI & $<.0001$ \\
\hline UNT vs. NEG & 0.0028 \\
\hline
\end{tabular}

B

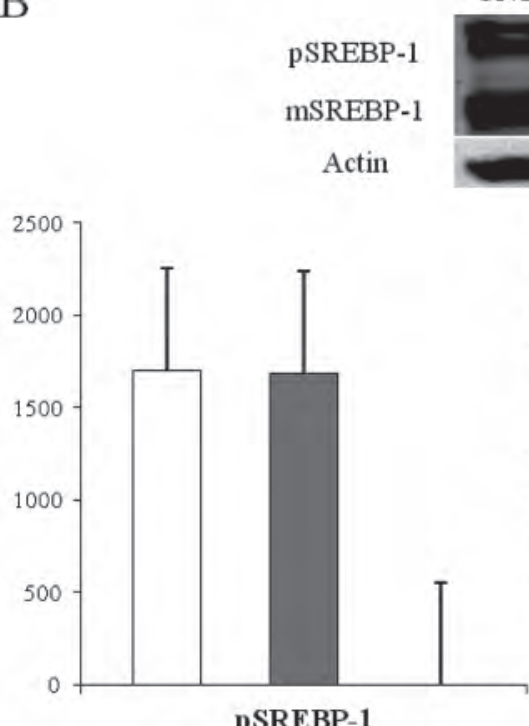

pSREBP-1

\begin{tabular}{|c|c|}
\hline Contrast & $P$ value \\
\hline (UNT+NEG) vs. SSI & $<.0001$ \\
\hline UNT vs. NEG & 0.97 \\
\hline
\end{tabular}

UNT NEG SSI

UNT NEG SSI
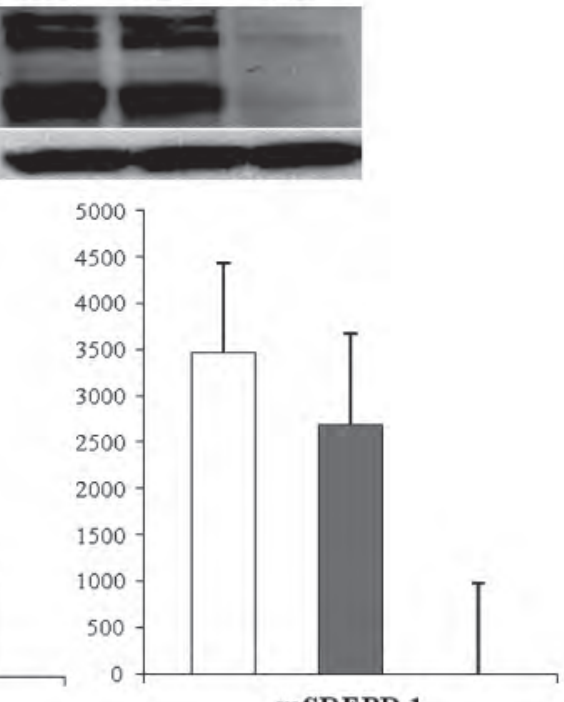

MSREBP-1

\begin{tabular}{|c|c|}
\hline Contrast & $P$ value \\
\hline (UNT+NEG) vs. SSI & $<.0001$ \\
\hline UNT vs. NEG & 0.26 \\
\hline
\end{tabular}

C

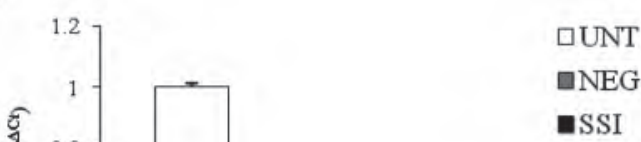

D

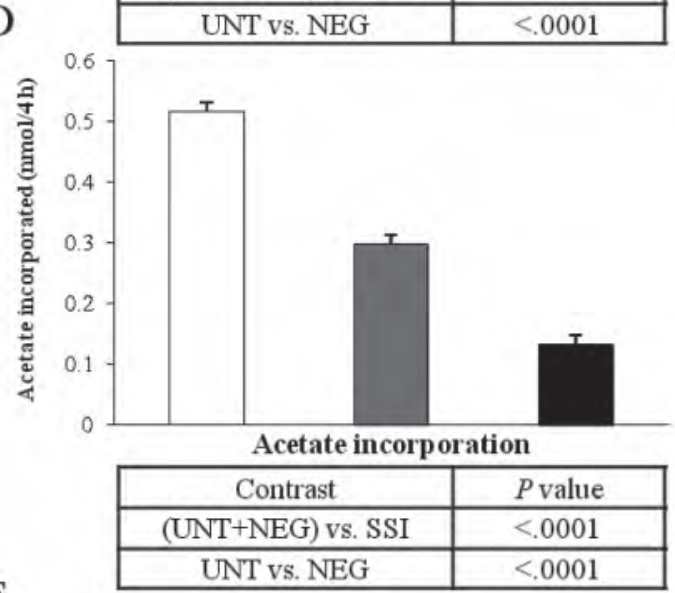

E

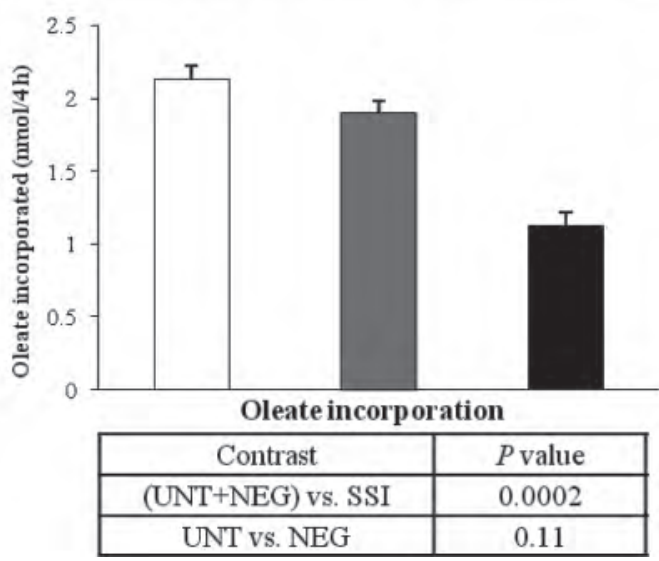

Figure 1. The expression of sterol regulatory element binding protein (SREBP)-1 mRNA, SREBP-1 proteins, S14 mRNA, acetate incorporation, and oleate incorporation in cells treated with SREBP-1 specific small interfering (si)RNA. Bovine mammary epithelial cells (MAC-T cell line) were treated with transfection reagent only (UNT), a nontargeting siRNA sequence with transfection reagent (NEG), or an SREBP-1 specific siRNA with transfection reagent (SSI) at $100 \mathrm{n} M$ for $48 \mathrm{~h}$. Experiments were repeated 4 times. Fold change of mRNA expression was calculated using the $2^{-\Delta \Delta \mathrm{Ct}}$ method. Protein bands were visualized and quantified using Quantity One software (Bio-Rad, Hercules, CA). Means $( \pm$ SEM) were compared using contrasts; difference was considered significant when $P<0.05$.

the regulation of FA synthesis and cholesterol synthesis, respectively (Horton, 2002). As a regulator of lipid synthesis, SREBP-1 has been studied extensively in different species (Brown and Goldstein, 1997). In bovine mammary gland, SREBP-1c is one of the mechanisms regulating milk fat synthesis (Bauman et al., 2008).

Although many studies have examined the responses of SREBP-1 and lipogenic genes to MFD, the specific 
A

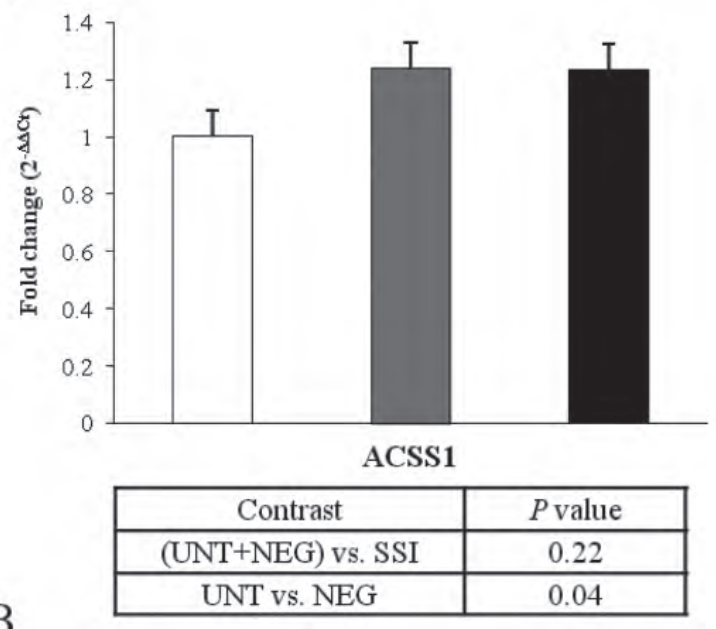

$\mathrm{B}$
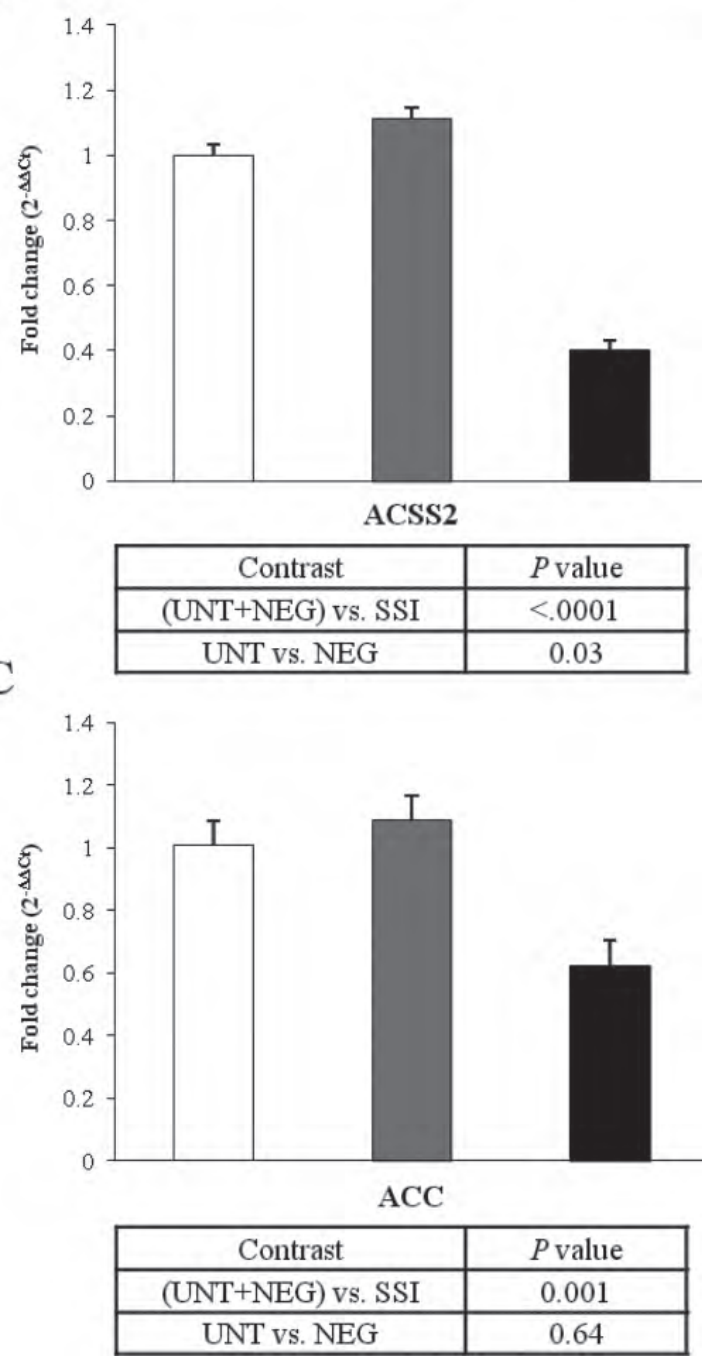

$\mathrm{D}$
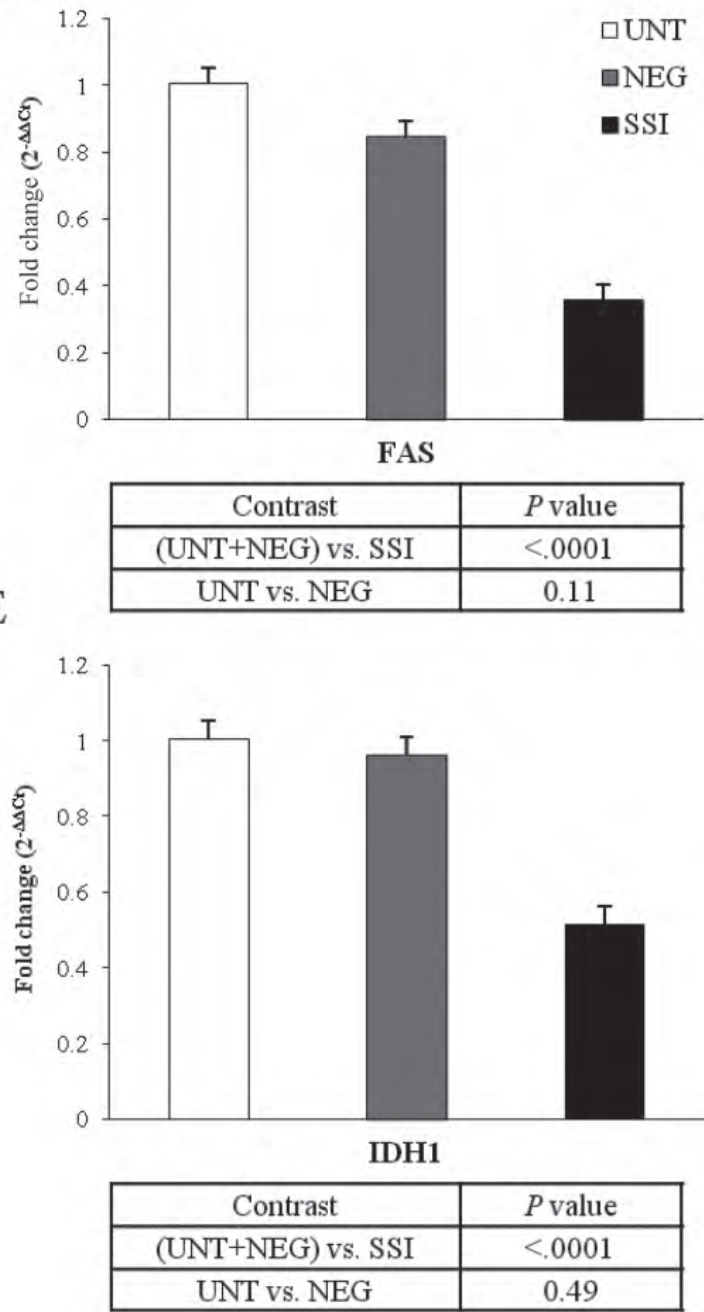

Figure 2. The mRNA expression of de novo lipogenic enzymes in cells treated with sterol regulatory element binding protein (SREBP)-1 small interfering (si)RNA. Bovine mammary epithelial cells (MAC-T cell line) were treated with transfection reagent only (UNT), a nontargeting siRNA sequence with transfection reagent (NEG), or an anti-SREBP-1 specific siRNA with transfection reagent (SSI) at $100 \mathrm{n} M$ for 48 h. Fold change of mRNA abundance was calculated using the $2^{-\Delta \Delta \mathrm{Ct}}$ method. Means ( \pm SEM) were compared using contrasts; difference was considered significant when $P<0.05$. 

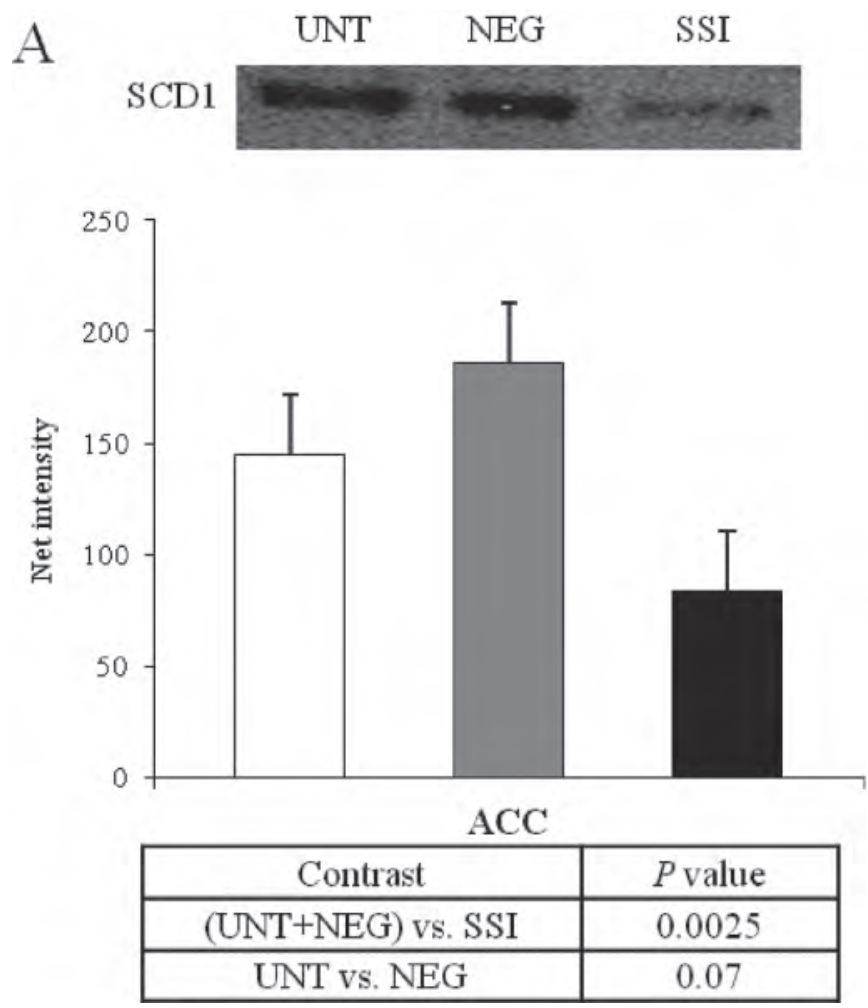

$\mathrm{B}$ UNT NEG SSI
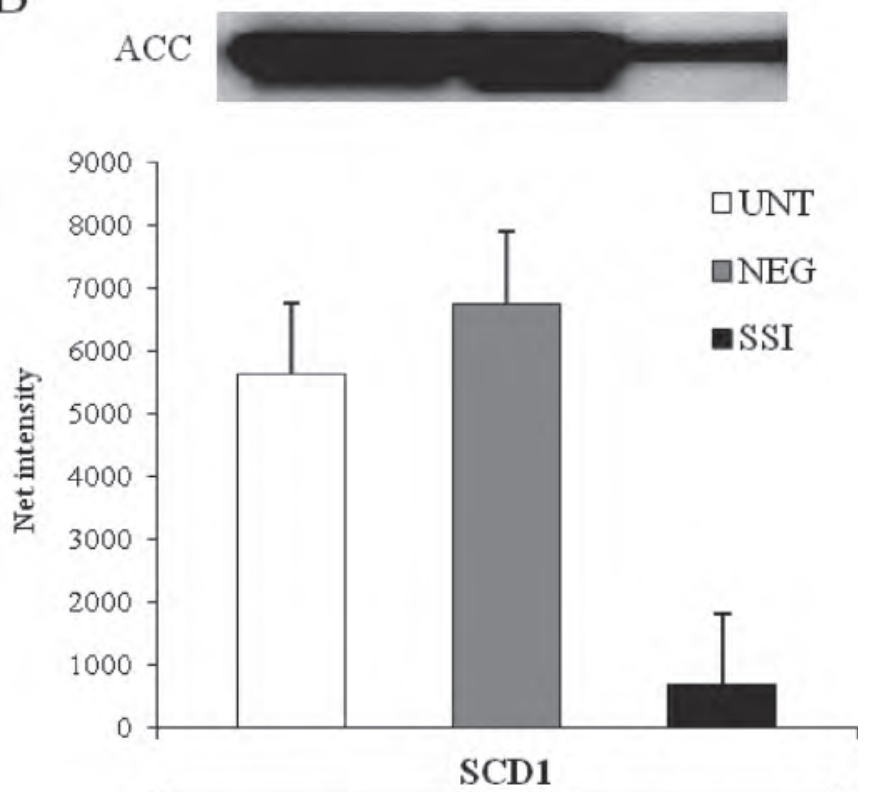

\begin{tabular}{|c|c|}
\hline Contrast & $P$ value \\
\hline (UNT+NEG) vs. SSI & 0.001 \\
\hline UNT vs. NEG & 0.34 \\
\hline
\end{tabular}

Figure 3. The protein levels of ACC and SCD1 in cells transfected with sterol regulatory element binding protein (SREBP)-1 small interfering (si)RNA. Bovine mammary epithelial cells (MAC-T cell line) were treated with transfection reagent only (UNT), a nontargeting siRNA sequence with transfection reagent (NEG), or an SREBP-1 specific siRNA with transfection reagent (SSI) at $100 \mathrm{nM}$ for $48 \mathrm{~h}$. Proteins were separated using electrophoresis. Protein bands were visualized and densitometry was quantified using Quantity One software (Bio-Rad, Hercules, CA). Means $( \pm$ SEM) were compared using contrasts; difference was considered significant when $P<0.05$.

role of SREBP-1 in regulating milk fat synthesis has not been directly evaluated. Trans-10,cis-12 CLA has been identified as a CLA isomer that causes MFD (Baumgard et al., 2000). Peterson et al. (2004) observed a reduction in mature SREBP-1 protein and mRNA expression of ACC, FAS, and SCD1 in MAC-T cells treated with trans-10,cis-12 CLA. Harvatine and Bauman (2006) also demonstrated a significant reduction of mammary mRNA abundance of SREBP-1, FAS, and lipoprotein lipase (LPL) in lactating dairy cows administered trans-10,cis-12 CLA or fed a low-forage and high-oil diet. In another abomasal infusion study, trans-10,cis-12 CLA not only resulted in reduced milk fat content and yield, but also led to decreased mRNA abundance of the genes encoding LPL, FABP3, ACC, FAS, SCD1, GPAT, and AGPAT (Baumgard et al., 2002). These enzymes are involved in FA transport and uptake, de novo fatty acid synthesis, desaturation of FA and triglyceride synthesis. Thus, it is speculated that SREBP-1 plays a role in regulating milk fat synthesis during MFD, but the relationship between SREBP-1 and lipogenic enzymes independent of potential regula- tion by other factors during MFD has not been fully elucidated.

In this study, RNA interference was used to knock down SREBP-1 in MAC-T cells cultured in medium containing insulin and prolactin to investigate the specific role of SREBP-1 in affecting the expression of genes encoding key enzymes of milk fat synthesis. Our SREBP-1-specific siRNA targeted a region of the transcript identical between SREBP-1a and SREBP-1c and did not distinguish the 2 isoforms. Both mRNA and protein levels of SREBP-1 decreased dramatically, indicating high efficiency of the siRNA in interfering with SREBP-1 expression. Spot 14 is a gene encoding a nuclear protein that is associated with the regulation of FA synthesis in lipogenic tissues, and it has been shown to be engaged in mammary regulation of milk fat synthesis (Harvatine and Bauman, 2006). In our study, S14 was dramatically reduced by SREBP-1 siRNA, indicating that S14 might be regulated by SREBP-1 in MAC$\mathrm{T}$ cells. However, it was also decreased in the negative control, which might be due to cell stress caused by transfection or similarity of random siRNA sequence 
A

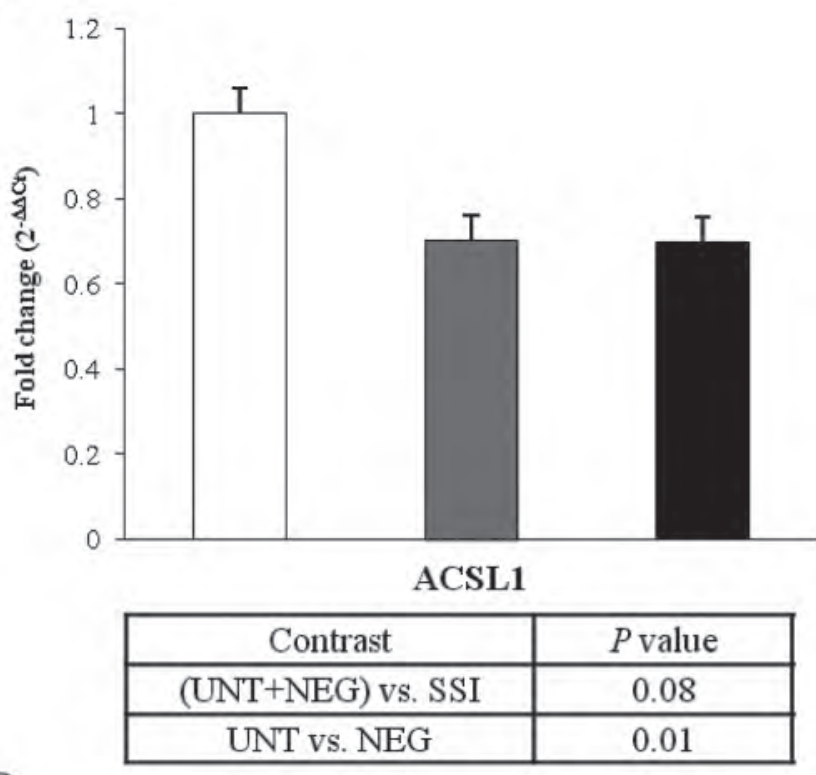

B

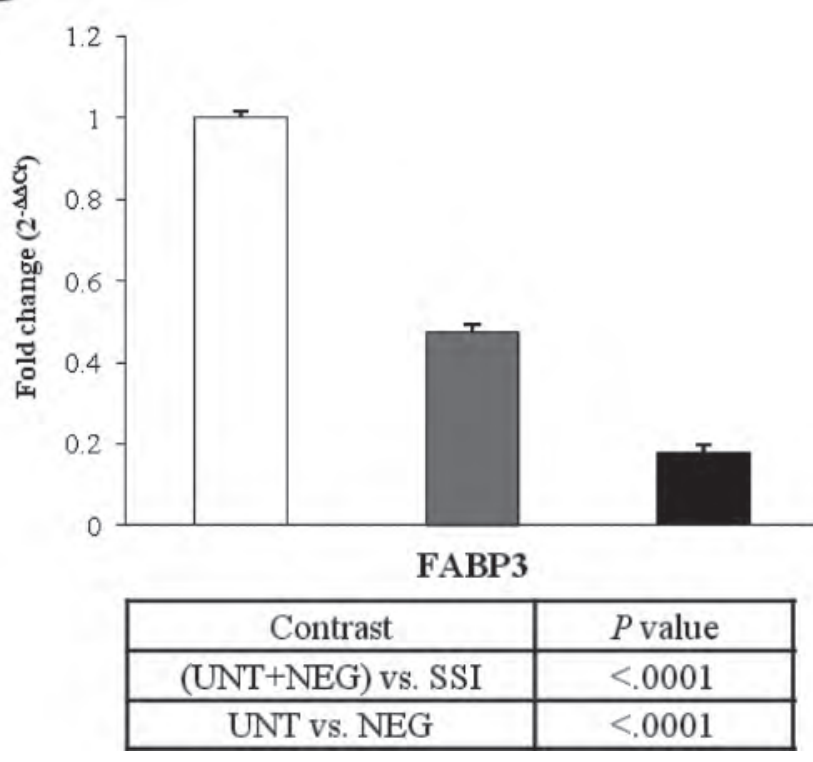

$\mathrm{C}$

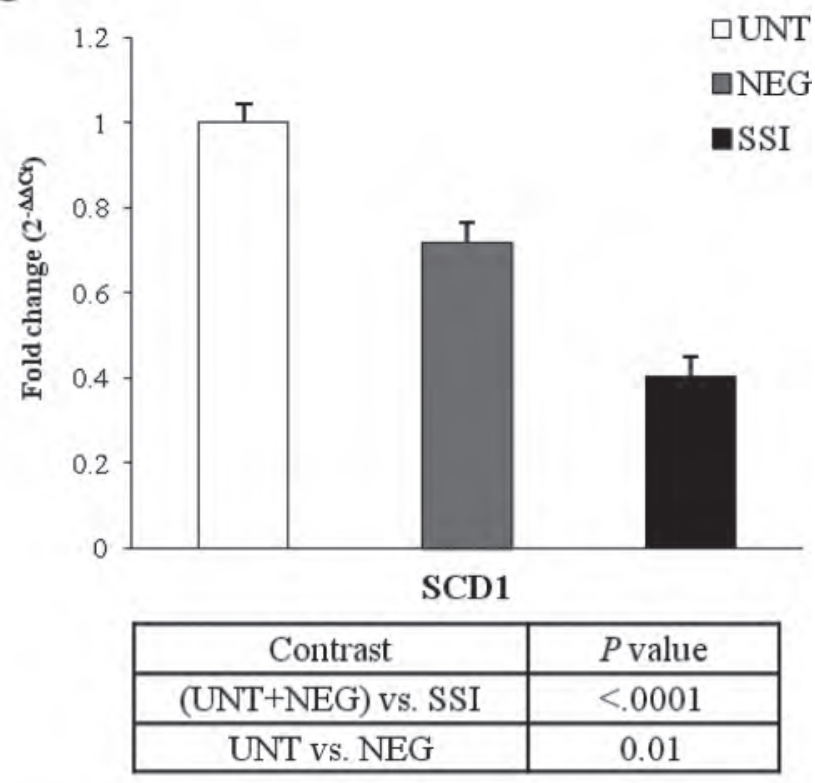

Figure 4. The mRNA abundance of ACSL1, FABP3, and SCD1 in cells transfected with sterol regulatory element binding protein (SREBP)-1 small interfering (si)RNA. Bovine mammary epithelial cells (MAC-T cell line) were treated with transfection reagent only (UNT), a nontargeting siRNA sequence with transfection reagent (NEG), or an SREBP-1 specific siRNA with transfection reagent (SSI) at $100 \mathrm{nM}$ for $48 \mathrm{~h}$. Real-time PCR was performed using corresponding primers. Fold change was calculated using the $2^{-\Delta \Delta \mathrm{Ct}}$ method. Means $( \pm$ SEM) were compared using contrasts; difference was considered significant when $P<0.05$.

and the S14 sequence. When SREBP-1 expression was reduced, FA synthesis and FA uptake were reduced as indicated by acetate and oleate incorporation data. Although both acetate and oleate incorporation were reduced, the magnitude of the reduction in acetate incorporation was greater than that of oleate incorporation, suggesting that de novo FA synthesis was affected to a greater extent during SREBP-1 knockdown. This is consistent with the milk FA profile in cows with MFD. Chouinard et al. (1999) demonstrated that the effects of MFD-inducing CLA were most pronounced on de novo fatty acid synthesis and the desaturation process. Similarly, SCD1 activity and de novo synthesized FA were extensively reduced when cows were infused with a high dose of trans-10,cis-12 CLA (Baumgard et al., 2001). 
A

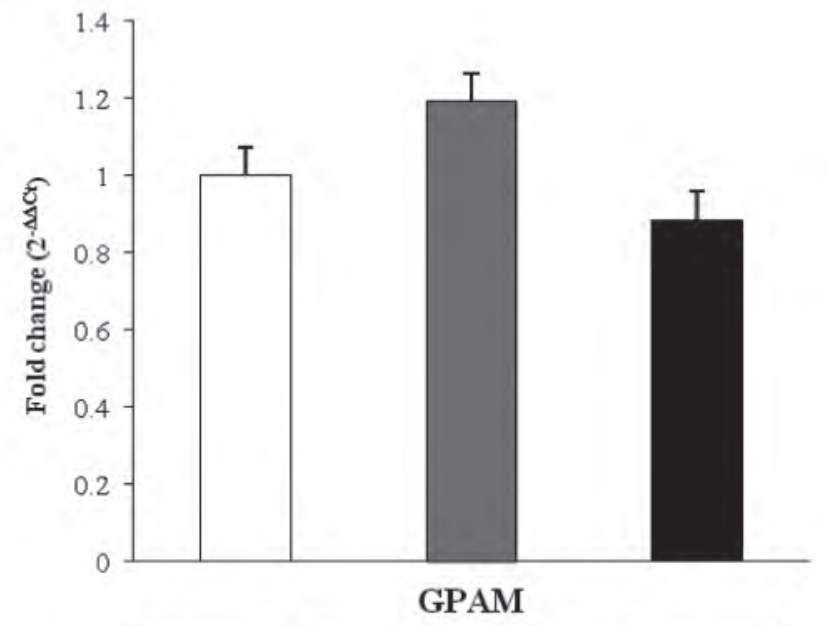

B

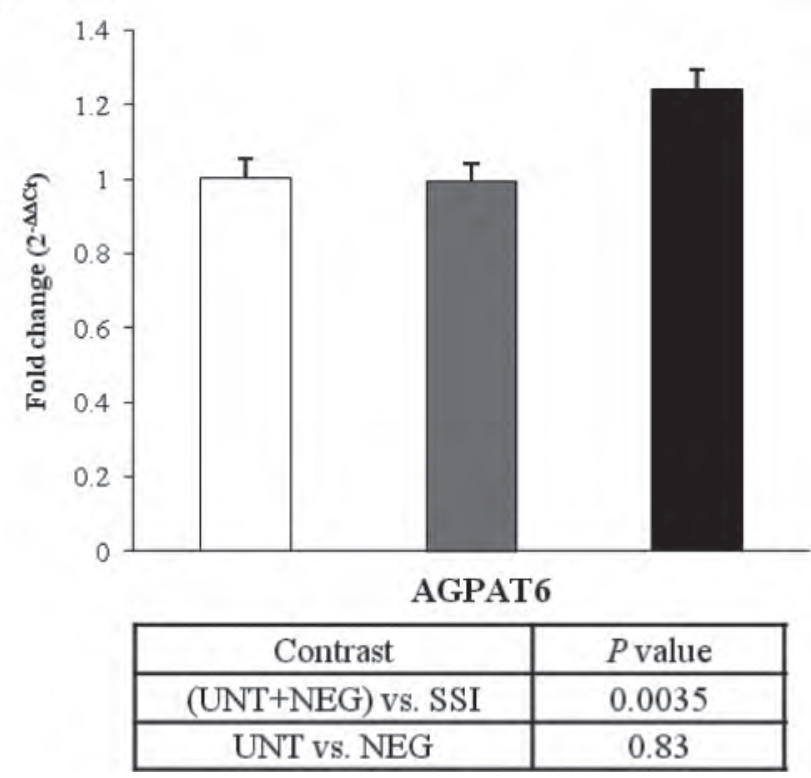

$\mathrm{C}$

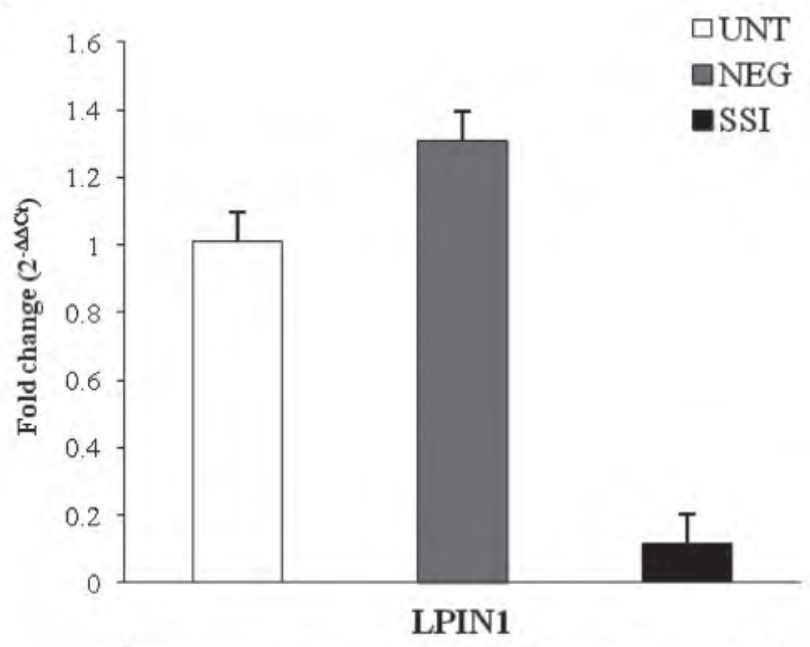

$\mathrm{D}$

\begin{tabular}{|c|c|}
\hline Contrast & $P$ value \\
\hline (UNT+NEG) vs. SSI & $<.0001$ \\
\hline UNT vs. NEG & 0.06 \\
\hline
\end{tabular}

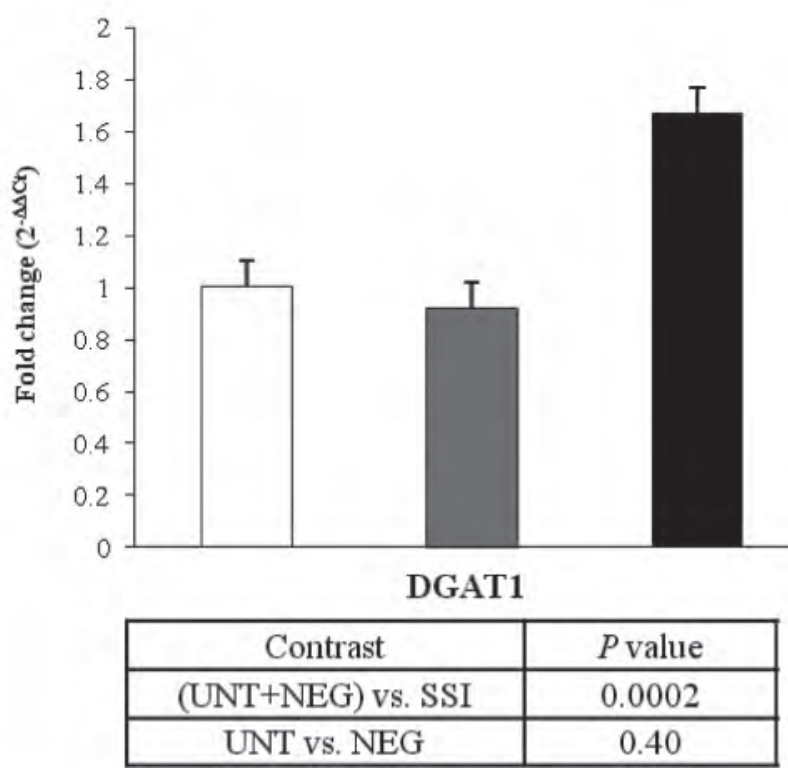

Figure 5. The mRNA abundance of genes encoding enzymes involved in triglyceride esterification in cells with sterol regulatory element binding protein (SREBP)-1 knockdown. Bovine mammary epithelial cells (MAC-T cell line) were treated with transfection reagent only (UNT), a nontargeting small interfering (si)RNA sequence with transfection reagent (NEG), or an SREBP-1 specific siRNA with transfection reagent (SSI) at $100 \mathrm{nM}$ for $48 \mathrm{~h}$. Real-time PCR was performed. Fold change of mRNA abundance was calculated using the $2^{-\Delta \Delta \mathrm{Ct}}$ method. Means $( \pm$ SEM) were compared using contrasts; difference was considered significant when $P<0.05$.

To test whether de novo lipogenic enzymes are regulated by SREBP-1, we measured the expression of genes encoding lipogenic enzymes involved in the de novo FA synthesis pathway. As the precursor for de novo FA synthesis, acetate needs to be activated by acyl-CoA synthetase enzymes to produce acetyl-CoA. Between the 2 isoforms, ACSS2 is more abundant than ACSS1 in the mammary gland during lactation (Bionaz and Loor, 2008b). Both ACSS1 and ACSS2 have high affinity for acetate, with ACSS2 showing greater affinity. Bovine ACSS1 also activates about 4 -fold more ${ }^{14} \mathrm{C}$-acetate toward $\mathrm{CO}_{2}$ than lipid, indicating that the acetyl-CoA produced by ACSS1 is mainly for the oxidative pathway (Fujino, 2001). Therefore, ACSS2 is the isoform responsible for acetate activation during de novo FA synthesis. In our study, ACSS2, but not ACSS1, was 
A

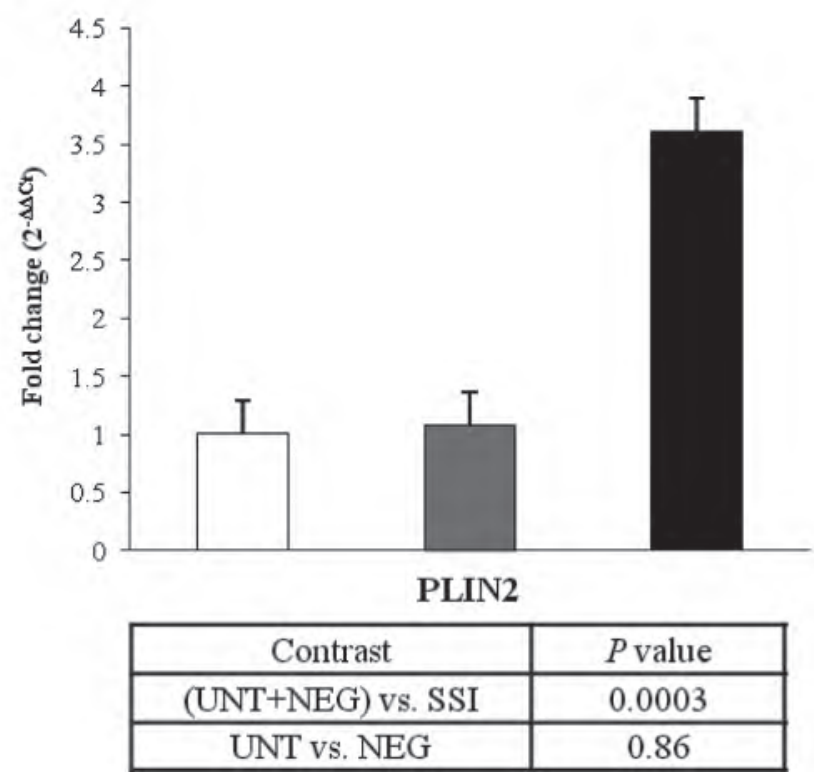

$\mathrm{B}$

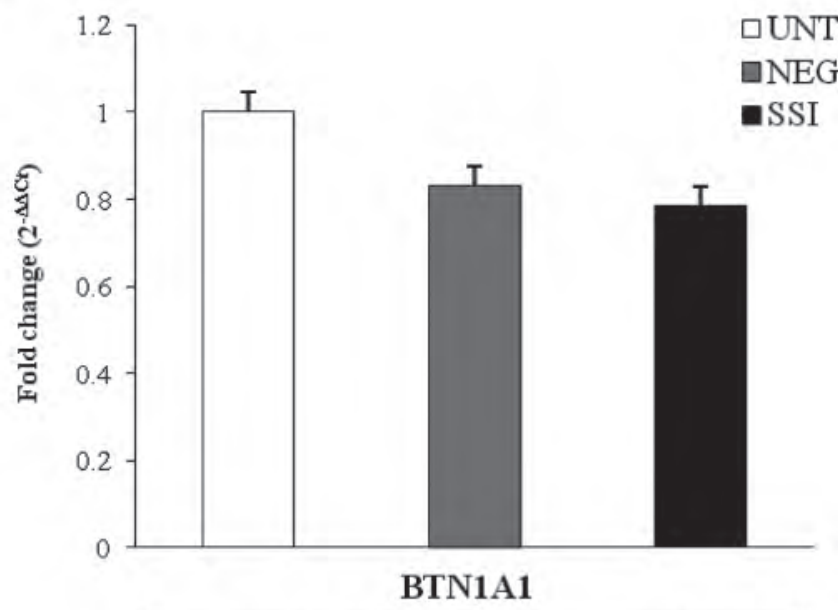

\begin{tabular}{|c|c|}
\hline Contrast & $P$ value \\
\hline (UNT+NEG) vs. SSI & 0.06 \\
\hline UNT vs. NEG & 0.04 \\
\hline
\end{tabular}

Figure 6. The mRNA expression of genes related to milk fat droplet formation and secretion in cells transfected with sterol regulatory element binding protein (SREBP)-1 small interfering (si)RNA. Bovine mammary epithelial cells (MAC-T cell line) were treated with transfection reagent only (UNT), a non-targeting siRNA sequence with transfection reagent (NEG), or an SREBP-1 specific siRNA with transfection reagent (SSI) at $100 \mathrm{n} M$ for $48 \mathrm{~h}$. Real-time PCR was performed. Fold change of mRNA abundance was calculated using the $2^{-\Delta \Delta \mathrm{Ct}}$ method. Means $( \pm$ SEM) were compared using contrasts; difference was considered significant when $P<0.05$.

downregulated by SREBP-1 inhibition, indicating that ACSS2 appears to be part of the SREBP-1-regulated lipid synthetic pathway.

After activation, acetyl-CoA is catalyzed by ACC to synthesize malonyl-CoA. Acetyl-CoA carboxylase is the rate-limiting step of de novo FA synthesis. During lactation, the targeting of FA precursors to the mammary gland is primarily driven through suppression of the activity of ACC in adipose tissue and induction of ACC in mammary gland, which is in part through corresponding changes in ACC mRNA levels in the 2 tissues, to satisfy the increased metabolic demand created by the requirement to milk fat synthesis and secretion (Clegg et al., 2000). Fatty acid synthetase is another key enzyme of de novo FA synthesis and is responsible for adding carbons to the FA chain to produce shortchain and medium-chain FA. In the current study, expression of both ACC and FAS was reduced with SREBP-1 suppression, indicating that transcription of ACC and FAS is regulated by SREBP-1. The reduction in ACC and FAS has also been observed in some MFD studies (Peterson et al., 2003). In another study with MAC-T cells, reduction in mature SREBP-1 protein with trans-10,cis-12 CLA corresponded to reductions in mRNA expression of ACC and FAS (Peterson et al., 2004). Taken together, ACC and FAS are both involved in the SREBP-1-regulated lipogenic pathway in MAC$\mathrm{T}$ cells and the reduction of these 2 enzymes during MFD is likely due to SREBP-1 inhibition.

Besides the enzymes mentioned above, IDH1 plays a role in FA biosynthesis by providing NADPH. Liu et al. (2006) found that IDH1 expression was reduced by trans-10, cis-12 CLA in the BME-UV bovine mammary epithelial cell line and proposed that the inhibitory effects of trans-10,cis-12 CLA on milk fat synthesis in mammary epithelial cells might derive, at least in part, from repression of IDH1 expression and reduced NADPH availability. In the current study, we also observed a significant reduction in IDH1 expression when SREBP-1 was inhibited by siRNA, indicating that IDH1 is one of the targets for SREBP-1, and decreased IDH1 during MFD might be regulated by reduced SREBP-1 level. High-glucose medium was used during transfection and this might decrease IDH1 activity. We did not measure IDH1 activity in the current study, but its mRNA level was indeed reduced by SREBP-1 knockdown.

Preformed long-chain FA from the diet and adipose lipolysis are also taken up by the mammary gland to synthesize milk fat. The activation of long-chain FA is catalyzed by ACSL enzymes. Six isoforms of ACSL have been identified, and ACSL1 has been shown to be the 
most abundant isoform in the lactating bovine mammary gland (Bionaz and Loor, 2008a). Upregulation of ACSL1 at the onset of lactation was also observed by Finucane et al. (2008). In the current study, ACSL1 was not affected by SREBP-1 knockdown, suggesting that SREBP-1 is not involved in the transcriptional regulation of long-chain FA activation by ACSL1. Similarly, when SREBP-1 expression was significantly decreased in bovine kidney cells treated with trans-10, cis-12 CLA, the expression of ACSL1 was not changed (Bionaz et al., 2012). Thus, ACSL1 seems not to be a target of SREBP-1. In fact, it has been demonstrated that ACSL1 is a peroxisome proliferated-activated receptor $\alpha$ target because its expression was upregulated by a peroxisome proliferated-activated receptor $\alpha$ agonist (Bionaz et al., 2012).

The transport of long-chain FA within the cell may be mediated by FABP, and it has been shown that FABP3 is the most abundant isoform in lactating bovine mammary gland (Bionaz and Loor, 2008a). Before addition to the glycerol backbone, some saturated long-chain FA, especially stearic acid, are modified by SCD1 to produce unsaturated FA. Thus, we measured the expression of FABP3 and SCD1 and found that both declined with SREBP-1 inhibition, indicating that transport and desaturation of long-chain FA are regulated transcriptionally by SREBP-1. Kadegowda et al. (2009) observed a dramatic decline in FABP3 in MAC-T cells treated with trans-10, cis-12 CLA. Evidence also exists for a significant reduction in SCD1 mRNA abundance from mammary tissue during abomasal infusion of trans-10,cis-12 CLA (Baumgard et al., 2002). Combining these data, FABP3 and SCD1 are involved in the SREBP-1-regulated pathway during milk fat synthesis.

During milk fat synthesis, FA from the de novo pathway or circulation are esterified to glycerol-3-phosphate to produce triglycerides. During this process, enzymes for adding FA to the 3 positions of glycerol backbone and for removing the phosphate group play key roles in controlling synthesis rates. These enzymes include GPAM (addition of FA to glycerol-3-phosphate), AGPAT6 (addition of FA to sn-2 position of acylglycerol3-phosphate), LPIN1 (phosphatidic acid phosphohydrolase activity), and DGAT1 (addition of FA to sn-3 position of diacylglycerol) (Bionaz and Loor, 2008a,b). After treatment with SREBP-1 siRNA, both GPAM and LPIN1 were decreased by SREBP-1 siRNA treatment, but the mRNA levels of AGPAT6 and DGAT1 were increased when SREBP-1 expression was reduced. The reduction in GPAM with SREBP-1 siRNA treatment in this study indicates that GPAM is controlled by SREBP-1 to affect milk fat synthesis. Two LPIN1 variants ( $\mathrm{a}$ and $\mathrm{b}$ ) have been described in mice (Péterfy et al., 2005); however, no bovine sequences distinguish between the 2 isoforms. The present data should be considered as the combination of the 2 variants. It has been demonstrated that LPIN1 was upregulated during lactation and downregulated in MAC-T cells treated with trans-10,cis-12 CLA (Bionaz and Loor, 2008a). Thus, LPIN1 plays a role in milk triglyceride synthesis, and the reduction during trans-10, cis-12 CLA treatment might result from decreased expression of SREBP-1. The increase in AGPAT6 was not expected and might be caused by compensatory effects of other transcription factors. Evidence exists that AGPAT6 has GPAT activity but no AGPAT activity in human kidney cells and mice, and it has been renamed GPAT4, suggesting that other AGPAT isoforms may play important roles in the second step of triglyceride synthesis (Chen et al., 2008; Nagle et al., 2008). Regardless of the specific role of AGPAT6, it is not regulated by SREBP-1 in bovine mammary epithelial cells. Because DGAT2 is thought to be adipocyte-specific and almost undetectable in the mammary gland, DGAT1 is more likely responsible for adding FA to the sn-3 position of diacylglycerol during milk fat synthesis (Bionaz and Loor, 2008b). The increase in DGAT1 in this study indicated that DGAT1 might not be regulated by SREBP-1. In fact, it has been shown that the expression of DGAT1 was not changed in MAC-T cells treated with trans-10,cis-12 CLA; however, its activity was significantly decreased (Sørensen et al., 2008). Instead, trans-10, cis-12 CLA may affect DGAT1 activity directly or through a posttranslational mechanism. Although these triglyceride esterification enzymes responded differently to SREBP-1 knockdown, the reduction in GPAM and LPIN1 expression might be enough to reduce triglyceride synthesis without reductions in AGPAT6 and DGAT1 because both of them are key enzymes for this step.

Because milk fat is secreted as milk fat globules enveloped by the milk fat globule membrane, we analyzed the expression of PLIN2 and BTN1A1, 2 milk fat droplet proteins, to determine the role of SREBP-1 in milk fat droplet formation (Nielsen et al., 1999). The sequence of bovine PLIN2 is identical to the sequence of bovine adipophilin in mammary gland. Adipophilin is associated with milk lipid globule membranes and its levels correlate with lipid droplet deposition (Heid et al., 1998). We observed an increase in PLIN2 and no change in BTN1A1 in cells treated with SREBP-1 siRNA, indicating that the regulatory role of SREBP-1 in milk lipid synthesis might be limited to FA synthesis, activation, transport, desaturation, and triglyceride esterification, but there is no SREBP-1 effect on transcription of genes involved in milk fat droplet 
formation or secretion. Another possibility is that fat droplets were not formed because MAC-T cells did not fully differentiate in culture. The fat droplet synthetic pathway might not have been activated and the genes were unable to respond to SREBP-1 knockdown.

Besides S14, some other measurements were also significantly affected by the negative control siRNA compared with the untransfected control. The changes may have resulted from cell stress caused by transfection or other nonspecific siRNA effects. The contrast between SREBP-1 siRNA treatment and controls ruled out possible nonspecific effects caused by transfection reagent and siRNA.

In our study, we focused on only one transcription factor in regulating the transcription of genes involved in milk fat synthesis. However, other factors regulate transcription, translation, and activity of lipogenic enzymes. We did not measure levels of other transcription factors, such as liver-X receptor and peroxisome proliferator-activated receptor $\gamma$, so the effect of these factors cannot be ruled out. When SREBP-1 is knocked down, liver-X receptor, peroxisome proliferator-activated receptor $\gamma$, and other factors might be responsible for maintaining the expression of some targets, so that no change or an increase in transcripts occurs. Because the ultimate, active form of enzymes is protein, processing during translation and activation cannot be ignored, and regulation of lipogenic enzymes may occur at both the transcriptional and translational levels. Although many studies have used knockout mice to study the role of SREBP-1 in lipid synthesis, it is very difficult to make knockout cows. Our in vitro experiments take advantage of RNA interference to knock down SREBP-1 and provide insights into how SREBP-1 regulates mammary epithelial cell lipid synthesis. However, milk fat synthesis is a more complicated process in vivo and can be affected by surrounding tissues and energy status of the cow.

\section{CONCLUSIONS}

In conclusion, SREBP-1 regulates lipid synthesis in bovine mammary epithelial cells by controlling the transcription of genes encoding enzymes involved in de novo FA synthesis, FA desaturation, long-chain FA uptake, and triglyceride esterification. However, transcription of PLIN2 and BTN1A1 is not regulated by SREBP-1.

\section{ACKNOWLEDGMENTS}

This project was supported by National Research Initiative Competitive Grant no. 2009-35204-05358 from the USDA National Institute of Food and Agriculture.

\section{REFERENCES}

Bauman, D. E., and J. M. Griinari. 2003. Nutritional regulation of milk fat synthesis. Annu. Rev. Nutr. 23:203-227.

Bauman, D. E., J. W. Perfield, K. J. Harvatine, and L. H. Baumgard. 2008. Regulation of fat synthesis by conjugated linoleic acid: Lactation and the ruminant model. J. Nutr. 138:403-409.

Baumgard, L. H., B. A. Corl, D. A. Dwyer, A. Sæbø, and D. E. Bauman. 2000. Identification of the conjugated linoleic acid isomer that inhibits milk fat synthesis. Am. J. Physiol. Reg. Integr. Comp. Physiol. 278:R179-R184.

Baumgard, L. H., E. A. Matitashvili, B. A. Corl, D. A. Dwyer, and D. E. Bauman. 2002. Trans-10, cis-12 conjugated linoleic acid decreases lipogenic rates and expression of genes involved in milk lipid synthesis in dairy cows. J. Dairy Sci. 85:2155-2163.

Baumgard, L. H., J. K. Sangster, and D. E. Bauman. 2001. Milk fat synthesis in dairy cows is progressively reduced by increasing supplemental amounts of trans-10, cis-12 conjugated linoleic acid (CLA). J. Nutr. 131:1764-1769.

Bionaz, M., and J. J. Loor. 2008a. ACSL1, AGPAT6, FABP3, LPIN1, and SLC27A6 are the most abundant isoforms in bovine mammary tissue and their expression is affected by stage of lactation. J. Nutr. 138:1019-1024.

Bionaz, M., and J. J. Loor. 2008b. Gene networks driving bovine milk fat synthesis during the lactation cycle. BMC Genomics 9:366.

Bionaz, M., B. J. Thering, and J. J. Loor. 2012. Fine metabolic regulation in ruminants via nutrient-gene interactions: Saturated longchain fatty acids increase expression of genes involved in lipid metabolism and immune response partly through PPAR- $\alpha$ activation. Br. J. Nutr. 107:179-191.

Brown, M. S., and J. L. Goldstein. 1997. The SREBP pathway: Regulation of cholesterol metabolism by proteolysis of a membranebound transcription factor. Cell 89:331-340.

Chen, Y. Q., M. S. Kuo, S. Li, H. H. Bui, D. A. Peake, P. E. Sanders, S. J. Thibodeaux, S. Chu, Y. W. Qian, Y. Zhao, D. S. Bredt, D. E. Moller, R. J. Konrad, A. P. Beigneux, S. G. Young, and G. Cao. 2008. AGPAT6 is a novel microsomal glycerol-3-phosphate acyltransferase. J. Biol. Chem. 283:10048-10057.

Chouinard, P. Y., L. Corneau, D. M. Barbano, L. E. Metzger, and D. E. Bauman. 1999. Conjugated linoleic acids alter milk fatty acid composition and inhibit milk fat secretion in dairy cows. J. Nutr. 129:1579-1584.

Clegg, R. A., M. C. Barber, L. Pooley, I. Ernens, Y. Larondelle, and M. T. Travers. 2000. Milk fat synthesis and secretion: Molecular and cellular aspects. Livest. Prod. Sci. 70:3-14.

Eberlé, D., B. Hegarty, P. Bossard, P. Ferre, and F. Foufelle. 2004. SREBP transcription factors: Master regulators of lipid homeostasis. Biochimie 86:839-848.

Finucane, K. A., T. B. McFadden, J. P. Bond, J. J. Kennelly, and F. Q. Zhao. 2008. Onset of lactation in the bovine mammary gland: Gene expression profiling indicates a strong inhibition of gene expression in cell proliferation. Funct. Integr. Genomics 8:251-264.

Fujino, T. 2001. Acetyl-CoA synthetase 2, a mitochondrial matrix enzyme involved in the oxidation of acetate. J. Biol. Chem. 276:11420-11426

Harvatine, K. J., and D. E. Bauman. 2006. SREBP1 and thyroid hormone responsive spot 14 (S14) are involved in the regulation of bovine mammary lipid synthesis during diet-induced milk fat depression and treatment with CLA. J. Nutr. 136:2468-2474.

Heid, H. W., R. Moll, I. Schwetlick, H. Rackwitz, and T. W. Keenan. 1998. Adipophilin is a specific marker of lipid accumulation in diverse cell types and diseases. Cell Tissue Res. 294:309-321.

Horton, J. D. 2002. SREBPs: Activators of the complete program of cholesterol and fatty acid synthesis in the liver. J. Clin. Invest. 109:1125-1131.

Ip, M. M., P. A. Masso-Welch, S. F. Shoemaker, W. K. Shea-Eaton, and C. Ip. 1999. Conjugated linoleic acid inhibits proliferation and induces apoptosis of normal rat mammary epithelial cells in primary culture. Exp. Cell Res. 250:22-34.

Kadegowda, A. K. G., M. Bionaz, L. S. Piperova, R. A. Erdman, and J. J. Loor. 2009. Peroxisome proliferator-activated receptor- $\gamma$ ac- 
tivation and long-chain fatty acids alter lipogenic gene networks in bovine mammary epithelial cells to various extents. J. Dairy Sci. 92:4276-4289.

Liu, W., S. C. Degner, and D. F. Romagnolo. 2006. Trans-10, cis12 conjugated linoleic acid inhibits prolactin-induced cytosolic NADP+-dependent isocitrate dehydrogenase expression in bovine mammary epithelial cells. J. Nutr. 136:2743-2747.

Livak, K. J., and T. D. Schmittgen. 2001. Analysis of relative gene expression data using real-time quantitative PCR and the $2^{-\triangle \Delta C T}$ method. Methods 25:402-408.

Nagle, C. A., L. Vergnes, H. Dejong, S. Wang, T. M. Lewin, K. Reue, and R. A. Coleman. 2008. Identification of a novel sn-glycerol3-phosphate acyltransferase isoform, GPAT4, as the enzyme deficient in Agpat6-/- mice. J. Lipid Res. 49:823-831.

Nielsen, R. L., M. H. Andersen, P. Mabhout, L. Berglund, T. E. Petersen, and J. T. Rasmussen. 1999. Isolation of adipophilin and butyrophilin from bovine milk and characterization of a cDNA encoding adipophilin. J. Dairy Sci. 82:2543-2549.

Péterfy, M., J. Phan, and K. Reue. 2005. Alternatively spliced lipin isoforms exhibit distinct expression pattern, subcellular localization, and role in adipogenesis. J. Biol. Chem. 280:32883-32889.

Peterson, D. G., L. H. Baumgard, and D. E. Bauman. 2002. Short communication: Milk fat response to low doses of trans-10, cis-12 conjugated linoleic acid (CLA). J. Dairy Sci. 85:1764-1766.
Peterson, D. G., E. A. Matitashvili, and D. E. Bauman. 2003. Diet-induced milk fat depression in dairy cows results in increased trans-10, cis-12 CLA in milk fat and coordinate suppression of mRNA abundance for mammary enzymes involved in milk fat synthesis. J. Nutr. 133:3098-3102.

Peterson, D. G., E. A. Matitashvili, and D. E. Bauman. 2004. The inhibitory effect of trans-10, cis-12 CLA on lipid synthesis in bovine mammary epithelial cells involves reduced proteolytic activation of the transcription factor SREBP-1. J. Nutr. 134:2523-2527.

Rudolph, M. C., J. L. McManaman, T. Phang, T. Russell, D. J. Kominsky, N. J. Serkova, T. Stein, S. M. Anderson, and M. C. Neville. 2007. Metabolic regulation in the lactating mammary gland: A lipid synthesizing machine. Physiol. Genomics 28:323-336.

Shimano, H. 2001. Sterol regulatory element-binding proteins (SREBPs): Transcriptional regulators of lipid synthetic genes. Prog. Lipid Res. 40:439-452.

Sørensen, B. M., E. Chris Kazala, G. K. Murdoch, A. F. Keating, C. Cruz-Hernandez, J. Wegner, J. J. Kennelly, E. K. Okine, and R. J. Weselake. 2008. Effect of CLA and other C18 unsaturated fatty acids on DGAT in bovine milk fat biosynthetic systems. Lipids 43:903-912. 